\title{
Protein energy supplementation of usual hospital diet did not improve outcomes in inpatients with recent stroke
}

Dennis MS, Lewis SC, Warlow C. Routine oral nutritional supplementation for stroke patients in hospital (FOOD): a multicentre randomised controlled trial. Lancet 2005;365:755-63.

Does routine oral protein energy supplementation of a usual hospital diet improve outcomes in patients admitted with recent stroke?

\section{METHODS}

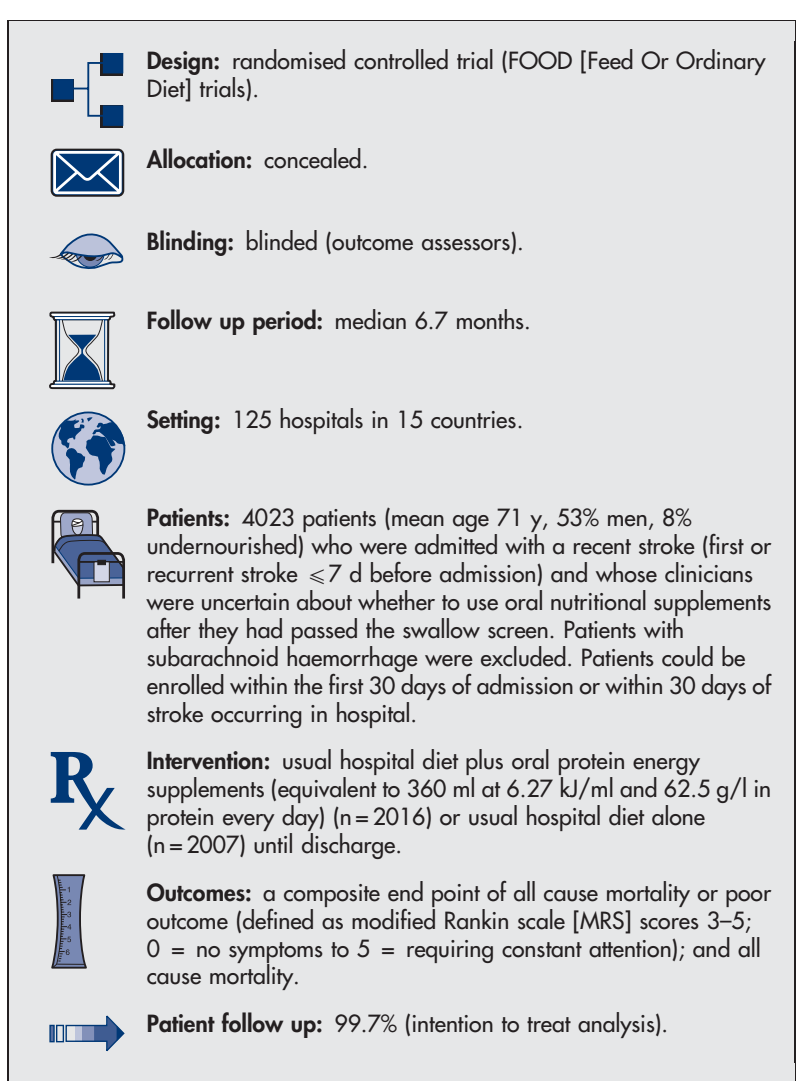

\section{MAIN RESULTS}

The groups did not differ for rates of the composite outcome or all cause mortality (table). For correspondence: Professor M Dennis, Western General Hospital, Edinburgh, UK. martin.dennis@ed.ac.uk

Sources of funding: National Health Service Research and Development, UK; Stroke Association; Chief Scientist Office of the Scottish Executive; Chest, Heart and Stroke, Scotland; and Royal Australasian College of Physicians.

\section{CONCLUSION}

Routine oral protein energy supplementation of a usual hospital diet did not improve outcomes in patients admitted with recent stroke.

\section{A modified version of this abstract appears in ACP Journal Club.}

\section{Commentary}

Nourc utritional status at stroke onset is a prognostic factor for stroke outcome. ${ }^{1}$ The relation between feeding and stroke outcomes were investigated by Dennis et al. The trial showed that routine oral protein energy supplementation did not lead to better outcomes in all stroke patients. However, the results did suggest a potential benefit for patients who were undernourished at hospital admission.

Study strengths included use of centralised randomisation, high follow up rates, and data collection systems that enabled the recruitment of a large number of patients.

The FOOD trial is clinically important because it highlights the issue of nutrition and its relation to health outcomes. Further research is needed to investigate the benefits of oral supplementation in malnourished patients at stroke onset.

Nurses have a vital role in early recognition and management of complications associated with feeding difficulties and malnutrition. ${ }^{2}$ Malnutrition is a commonly occurring, yet often unrecognised problem in patients with stroke. ${ }^{3}$ Although it makes intuitive sense to routinely add nutritional supplements to the diet of all patients with stroke, the FOOD trial did not support this practice. This observation reinforces the need for nurses to incorporate a series of standardised nutritional screens into the admission assessments and ongoing reassessments of all patients with stroke. ${ }^{4}$ The use of such nutritional screens in the context of a patient centred approach to care will guide nurses in their use of nutritional supplements in patients with stroke.

Cami D'Uva, RN, MN, ACNP Charmaine Martin, RN, MSc(T), ACNP Integrated Stroke Unit, Hamilton Health Sciences Hamilton, Ontario, Canada

1 Dávalos A, Ricart W, Gonzalez-Huix F, et al. Effect of malnutrition after acute stroke on clinical outcome. Stroke 1996;27:1028-32.

2 Westergren A, Ohlsson O, Rahm Hallberg I. Eating difficulties, complications and nursing interventions during a period of three months after a stroke. J Adv Nurs 2001;35:416-26.

3 Gosney M. Are we wasting our money on food supplements in elder care wards? J Adv Nurs 2003;43:275-80.

4 Finestone HM, Greene-Finestone LS. Rehabilitation medicine: 2. Diagnosis of dysphagia and its nutritional management for stroke patients. CMAJ 2003;169:1041-4

Usual hospital diet plus oral protein energy supplements $v$ usual hospital diet alone in patients admitted with recent stroke*

\begin{tabular}{lllll}
\hline Outcomes at median 6.7 months & Supplements & No supplements & RRI (95\% Cl) & NNH \\
\hline Composite endpoint & $59 \%$ & $58 \%$ & $1.5 \%(-3.6$ to 6.9) & Not significant \\
\hline & & & RRR (CI) & NNT \\
\hline All cause mortality & $12 \%$ & $13 \%$ & $5.2 \%(-11.8$ to 19.6) & Not significant \\
\hline
\end{tabular}

*Composite endpoint = all cause mortality or poor outcome defined as modified Rankin scale scores 3-5 (range 0-5). Abbreviations defined in glossary; RRI, RRR, $\mathrm{NNH}, \mathrm{NNT}$ and $\mathrm{Cl}$ calculated from data in article. 